\title{
Side Resistance of Drilled Shafts Socketed into Rocks for Serviceability and Ultimate Limit States
}

\author{
Yit-Jin Chen*, Cheng-Chieh Hsiao, Anjerick Topacio \\ Department of Civil Engineering, Chung Yuan Christian University, Taoyuan, Taiwan \\ Received 26 April 2019; received in revised form 08 August 2019; accepted 04 October 2019 \\ DOI: https://doi.org/10.46604/aiti.2020.4155
}

\begin{abstract}
This study evaluates the analysis models of side resistance in rock sections by utilizing a wide variety of load test data. Available analytical models including the empirical adhesion factor versus the rock's uniaxial compressive strength and its root are analyzed and compared statistically to determine the optimum relationships. The interpretation criteria for the $\mathrm{L}_{1}$ and $\mathrm{L}_{2}$ methods are used to analyze the load test results for serviceability and ultimate limit states, respectively. The analysis results show that the relationship model with the empirical adhesion factor versus the root of the rock's uniaxial compressive strength exhibits better correlation than the one with the rock's uniaxial compressive strength. Moreover, the general coordinate axes regression equation demonstrates better reliability than the semi-logarithmic and full logarithmic axes equations for both limit states. Based on these analyses, specific design recommendations for the side resistance of drilled shafts socketed into rocks are developed and provided with the appropriate statistics to verify their reliability.
\end{abstract}

Keywords: drilled shaft, socketed into rock, side resistance, statistical analysis

\section{Introduction}

Limited land for building structures frequently lead to the construction of high buildings to save land occupancy. The structures of such buildings are heavy. To stabilize these structures, a deep foundation is often used to transfer the load of the superstructure to the underlying bearing layer. Occasionally, a certain length of the pile foundation is embedded into the rock layer to increase the effects of stabilizing the superstructure.

Among pile foundations, drilled shafts (also called cast-in-place piles, drilled piers, or bored piles) are frequently used as deep foundation because they produce less noise and vibration during construction and meet the required pile diameter and depth. In addition, drilled shafts can provide sufficient lateral support to resist the force of the superstructure from earthquakes and wind loads.

When a pile is subjected to an axial load, the load is transmitted along the length of the pile toward the hard soil or rock layer, as shown in Fig. 1. Pile capacity includes side and tip resistances for resisting axial load. Side resistance plays an important role when a pile is socketed into rocks.

In the analysis of side resistance, the analysis concept of the shaft in cohesive soil and rocks is the same. In cohesive soil, the total stress analysis method is frequently used to evaluate unit side resistance $\left(f_{s}\right)$. The $\mathrm{f}_{\mathrm{s}}$ value can be computed on the basis of an empirical coefficient $(a)$, which is the adhesion factor between the soil and the shaft, and the average soil undrained shear

* Corresponding author. E-mail address: yjc@cycu.edu.tw

Tel.: +886-3-2654227; Fax: +886-3-2654299 
strength $\left(S_{u}\right)$ over the shaft length. Moreover, the $\alpha$ value is related to $S_{u}$, and the initial $a$ - $S_{u}$ relationship of the drilled shafts was developed by Stas and Kulhawy [1], as shown in Fig. 2. However, the $S_{u}$ values in their analysis were obtained from random test types. The $S_{u}$ value can be determined from various test types, but the results present an evident difference. Therefore, Chen and Kulhawy [2,3] later adopted a unique test type for $S_{u}$ from the consolidated isotropically undrained triaxial compression $(C I U C)$ test, which is denoted as $S_{u}(C I U C)$, the reference plane for a consistent test. The improved $a_{C I U C}-S_{u}(C I U C)$ relation is illustrated in Fig. 3. The data distribution of the improved $a_{C I U C^{-}} S_{u}(C I U C)$ correlation is superior to that of the previous result shown in Fig. 2. These concepts have been expanded to the analysis of side resistance for driven precast concrete piles $[4,5]$.

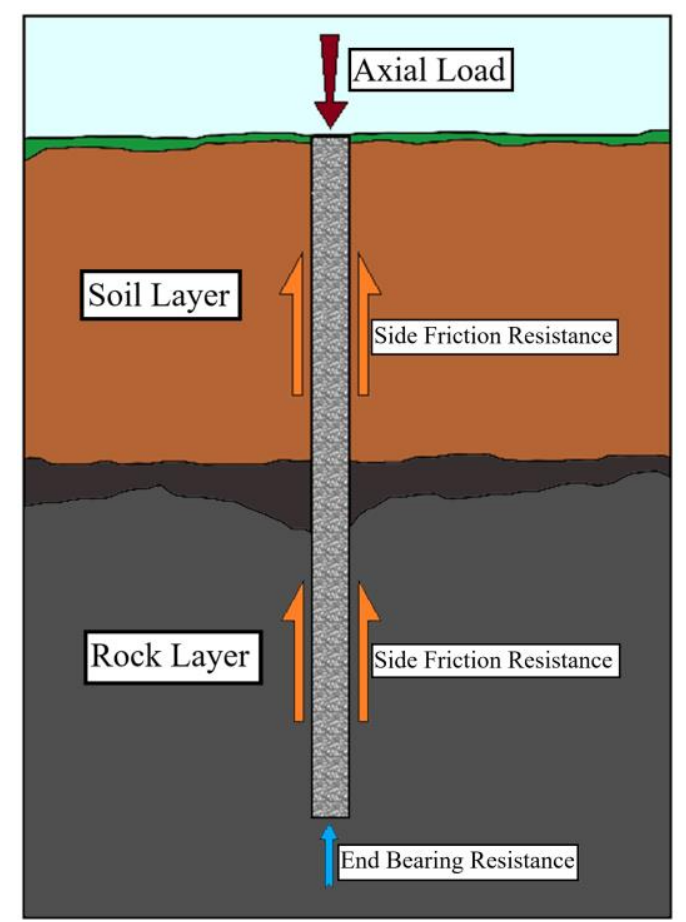

Fig. 1 Axial load resisted by a pile foundation

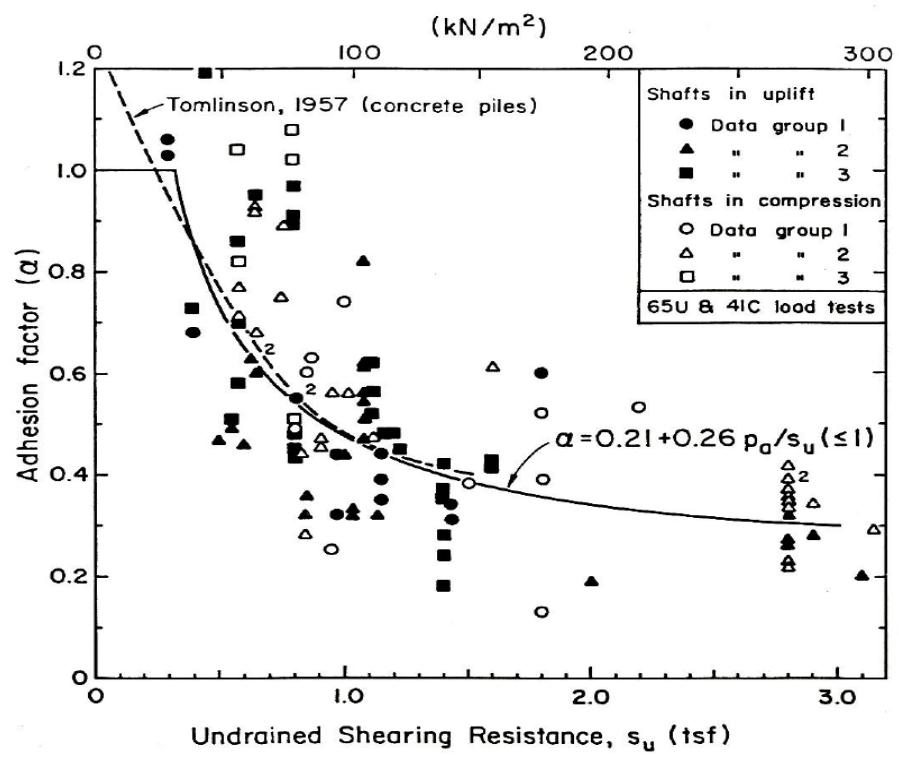

Fig. 2 Early $a-S_{u}$ relation [1]

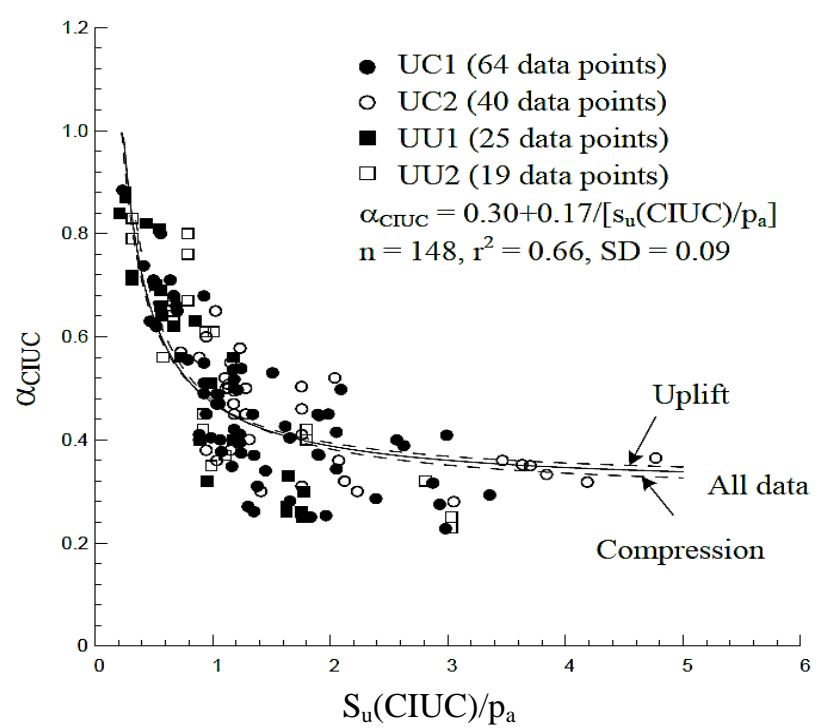

Fig. 3 Improved $a_{C I U C}-S_{u}(C I U C)$ relation [2,3]

The analysis model of side resistance for drilled shafts socketed into rocks is similar to the conventional total stress analysis in cohesive soil. However, the uniaxial compressive strength $\left(q_{u}\right)$ is adopted in rocks instead of the $S_{u}$ in cohesive soil. The $f_{s}$ value expressed by using $q_{u}$ or its rootz $\left(\sqrt{q_{u}}\right)$ can be expressed as: 


$$
\begin{aligned}
& f_{s}=\alpha \cdot q_{u} \\
& f_{s}=\alpha \cdot \sqrt{q_{u}}
\end{aligned}
$$

Accordingly, numerous studies have been conducted and have resulted in various relationships in determining the side resistance value of drilled shafts. Kulhawy and Goodman [6] recommended an $\alpha$ value of 0.15 and found that the value of $q_{u}$ should be less than $5 \mathrm{MPa}$. They used Eq. (1) to determine side resistance. Moreover, several researchers have utilized Eq. (2) to determine side resistance during analyses. Hooley and Brooks [7] studied the friction force of piles in overcompacted clay, soft rock, and weathered rock. They recommended a $q_{u}$ value between 0.25 and 3.0 MPa and an $\alpha$ value of 0.15 . The American Association of State Highway and Transportation Officials [8] suggested that the $q_{u}$ value should be less than $40 \mathrm{MPa}$ and the $\alpha$ value should be between 0.03 and 0.04 . Horvath et al. [9] suggested that the $q_{u}$ value should be less than $40 \mathrm{MPa}$, and the $\alpha$ value should be between 0.2 and 0.3 . Ku et al. [10] conducted related research on the western soft rock of Taiwan and recommended an $\alpha$ value of 0.16-0.21 but did not recommend any value for $q_{u}$. Lastly, Yang et al. [11] found that the $\alpha$ value of piles socketed into rocks in Northern Taiwan is between 0.1 and 0.5 , and the relation $\alpha$ versus $\sqrt{q_{u}}$ is shown in Fig. 4 .

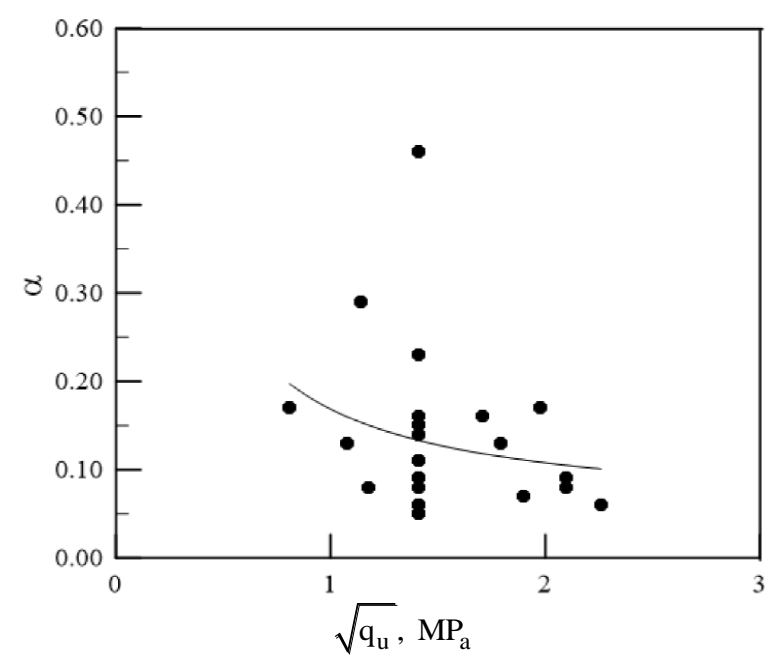

Fig. $4 \alpha-\sqrt{q_{u}}$ relationship based on northern Taiwan's load tests [11]

The aforementioned descriptions indicate that the current relations are based on a few load test data, and the range of the values of $\alpha$ is extremely broad and scattered. Thus, the current study was conducted to reassess side resistance for the serviceability limit state (SLS) and ultimate limit state (ULS) of drilled shafts socketed into rocks. Moreover, the various influencing factors were analyzed to provide a reliable design recommendation.

\section{Database for Analysis}

To evaluate the side resistance behavior of drilled shaft foundations socketed into rock sections, this study collected data from Taiwan, Turkey, the USA, Italy, and Singapore [12]. A total of 44 load tests embedded into rocks were obtained, including 28 sandstones, 3 mudstones, 3 limes, 3 soft sandstones, 3 hard shales, 2 tuffs, and 3 amphibolite. In addition, 81 sets of pile load data instruments were used from these load tests. Therefore, one load test may consist of several instruments for different rock sections. The average $a$ and $q_{u}$ values were adopted for the analysis of each load test. The collected pile information was accompanied by soil/rock layer information, pile foundation information, load-displacement curve, and load distribution curve along the pile length. Table 1 provides the details for the geometries, geotechnical parameters, and interpreted results of these load test data. Table 2 lists the statistical summary of these data [12]. 
Table 1 Geometries, geotechnical parameters, and interpreted results of load test data

\begin{tabular}{|c|c|c|c|c|c|c|}
\hline \multirow{2}{*}{ Shaft No. } & Depth, D & Diameter, B & $\begin{array}{l}\text { Test depth from } \\
\text { GL }\end{array}$ & $\mathrm{q}_{\mathrm{u}}$ & $f_{s}\left(L_{1}\right)^{1}$ & $f_{s}\left(L_{2}\right)^{2}$ \\
\hline & (m) & (m) & $(\mathrm{m})$ & $(\mathrm{MPa})$ & $(\mathrm{MPa})$ & $(\mathrm{MPa})$ \\
\hline TP1 & 37.6 & 0.95 & $28.0 \sim 36.0$ & 12.77 & 0.268 & 0.63 \\
\hline TP2 & 42.6 & 0.95 & $34.2 \sim 41.0$ & 10.01 & 0.176 & 0.53 \\
\hline TP3 & 20.0 & 1.2 & $4.0 \sim 19.0$ & 0.60 & 0.063 & 0.16 \\
\hline TP4 & 66.0 & 1.5 & $61.5 \sim 66.0$ & 4.17 & 0.160 & 0.59 \\
\hline TP5 & 25.5 & 1.5 & $21.5 \sim 25.5$ & 0.20 & 0.088 & 0.24 \\
\hline TP6 & 48.0 & 1.5 & $40.0 \sim 48.0$ & 1.21 & 0.095 & 0.31 \\
\hline TP7 & 48.0 & 1.5 & $40.0 \sim 48.0$ & 0.80 & 0.080 & 0.25 \\
\hline TP8 & 53.0 & 1.5 & $49.5 \sim 53.0$ & 1.03 & 0.110 & 0.52 \\
\hline TP9 & 30.0 & 1.2 & $26.4 \sim 30.0$ & 2.26 & 0.070 & 0.24 \\
\hline TP10 & 53.5 & 2.0 & $37.2 \sim 53.3$ & 2.46 & 0.060 & 0.22 \\
\hline TP11 & 54.5 & 2.0 & $38.2 \sim 54.5$ & 0.34 & 0.069 & 0.17 \\
\hline TP12 & 24.0 & 0.8 & $16.7 \sim 24.0$ & 0.70 & 0.018 & 0.11 \\
\hline TP13 & 48.0 & 1.5 & $47.7 \sim 52.0$ & 0.65 & 0.090 & 0.13 \\
\hline TP14 & 47.7 & 1.2 & $41.7 \sim 47.7$ & 0.16 & 0.115 & 0.14 \\
\hline TP15 & 59.0 & 1.2 & $55.8 \sim 59.0$ & 3.00 & 0.110 & 0.29 \\
\hline TP16 & 29.0 & 1.2 & $24.9 \sim 29.0$ & 0.13 & 0.060 & 0.16 \\
\hline TP17 & 45.0 & 1.2 & $35.0 \sim 42.5$ & 3.47 & 0.062 & 0.20 \\
\hline TP18 & 38.0 & 1.0 & $35.0 \sim 37.4$ & 13.00 & 0.150 & 0.37 \\
\hline TP19 & 60.4 & 1.5 & $58.4 \sim 59.8$ & 13.70 & 0.300 & 0.58 \\
\hline TP20 & 48.0 & 1.5 & $44.5 \sim 48.0$ & 13.64 & 0.277 & 1.15 \\
\hline TP21 & 46.0 & 0.41 & $43.4 \sim 45.3$ & 2.54 & 0.160 & 0.53 \\
\hline TP22 & 10.0 & 1.2 & $2.5 \sim 10.0$ & 1.30 & 0.053 & 0.21 \\
\hline TP23 & 9.1 & 1.2 & $3.5 \sim 9.1$ & 1.60 & 0.050 & 0.22 \\
\hline TP24 & 8.0 & 1.2 & $4.5 \sim 8.0$ & 1.00 & 0.050 & 0.20 \\
\hline TP25 & 25.0 & 1.0 & $15.5 \sim 25.5$ & 4.26 & 0.135 & 0.53 \\
\hline TP26 & 17.0 & 1.8 & $3.0 \sim 16.4$ & 1.70 & 0.064 & 0.24 \\
\hline TP27 & 36.0 & 1.0 & $32.9 \sim 35.4$ & 1.03 & 0.092 & 0.18 \\
\hline TP28 & 27.5 & 1.2 & $25.5 \sim 27.0$ & 1.51 & 0.075 & 0.47 \\
\hline TP29 & 22.8 & 0.8 & $12.3 \sim 22.2$ & 0.52 & 0.110 & 0.35 \\
\hline TP30 & 20.4 & 0.8 & $15.5 \sim 19.8$ & 1.86 & 0.111 & 0.30 \\
\hline TP31 & 26.4 & 1.0 & $16.8 \sim 26.8$ & 0.32 & 0.082 & 0.23 \\
\hline TP32 & 8.7 & 0.7 & $5.6 \sim 8.8$ & 5.00 & 0.227 & 0.50 \\
\hline TP33 & 11.0 & 0.7 & $5.6 \sim 11.0$ & 5.00 & - & 0.40 \\
\hline TP34 & 18.5 & 1.2 & $11.0 \sim 18.5$ & 0.90 & 0.100 & 0.15 \\
\hline TP35 & 39.0 & 1.2 & $26.0 \sim 37.0$ & 3.00 & 0.046 & 0.20 \\
\hline TP36 & 13.5 & 1.2 & $11.0 \sim 13.5$ & 6.00 & 0.148 & 0.42 \\
\hline TP37 & 7.3 & 0.7 & $2.1 \sim 7.3$ & 6.82 & 0.133 & 0.46 \\
\hline TP38 & 13.5 & 1.35 & $4.0 \sim 10.0$ & 7.00 & 0.080 & 0.34 \\
\hline TP39 & 11.5 & 1.5 & $3.5 \sim 9.6$ & 7.77 & 0.088 & 0.40 \\
\hline TP40 & 59.0 & 1.2 & $54.6 \sim 58$ & 0.26 & 0.050 & 0.26 \\
\hline TP41 & 73.0 & 1.5 & $67.0 \sim 73.0$ & 0.30 & 0.053 & 0.15 \\
\hline TP42 & 76.0 & 1.3 & $71.0 \sim 76.0$ & 0.45 & 0.012 & 0.22 \\
\hline TP43 & 40.7 & 2.2 & $28.5 \sim 39.5$ & 0.37 & 0.026 & 0.04 \\
\hline TP44 & 15.0 & 1.2 & $2.0 \sim 14.5$ & 0.93 & 0.053 & 0.14 \\
\hline
\end{tabular}

${ }^{1} f_{s}\left(L_{1}\right)$ is the unit friction interpreted from $L_{1}$ Method

${ }^{2} f_{s}\left(L_{2}\right)$ is the unit friction interpreted from $L_{2}$ Method

\section{Analysis Method}

Two methods were used in this study to obtain the side resistance of the drilled shaft foundation. First, the value was directly obtained from the t-z curve, which defines the shear stress-vertical displacement response of the soil at each particular depth. Second, the load-displacement curve and the load distribution curve throughout the pile length were utilized. By considering these test results, the interpretation of Kulhawy and Hirany (called the $L_{1}-L_{2}$ interpretation) [13] was adopted to construe unit side resistance under various limit states. 
Table 2 Statistics of load test data for analysis

\begin{tabular}{|c|c|c|c|c|c|c|c|c|}
\hline \multirow{2}{*}{$\begin{array}{l}\text { Interpretation } \\
\text { method }\end{array}$} & \multirow[b]{2}{*}{$\mathrm{n}$} & \multirow{2}{*}{$\begin{array}{c}\text { Statistical } \\
\text { Analysis }\end{array}$} & \multicolumn{3}{|c|}{ Pile Geometry } & \multirow{2}{*}{$\begin{array}{c}\mathrm{q}_{\mathrm{u}} \\
(\mathrm{MPa})\end{array}$} & \multirow[b]{2}{*}{$\alpha$} & \multirow{2}{*}{$\begin{array}{c}\mathrm{f}_{\mathrm{s}} \\
(\mathrm{MPa})\end{array}$} \\
\hline & & & $\begin{array}{l}\text { Pile length } \\
\text { D (m) }\end{array}$ & $\begin{array}{l}\text { Pile diameter } \\
\text { B }(\mathrm{m})\end{array}$ & $\mathrm{D} / \mathrm{B}$ & & & \\
\hline \multirow{4}{*}{$\mathrm{L}_{1}$} & \multirow{4}{*}{44} & Range & $7.3-76.0$ & $0.41-2.2$ & $6.7-112.2$ & $0.13-13.7$ & $0.011-0.719$ & $0.012-0.50$ \\
\hline & & Mean & 33.10 & 1.2 & 28.13 & 3.372 & 0.098 & 0.104 \\
\hline & & SD & 17.53 & 0.39 & 18.35 & 3.92 & 0.14 & 0.078 \\
\hline & & $\mathrm{COV}$ & 0.53 & 0.33 & 0.65 & 1.16 & 1.42 & 0.75 \\
\hline \multirow{4}{*}{$\mathrm{L}_{2}$} & \multirow{4}{*}{44} & Range & $7.3-76.0$ & $0.41-2.2$ & $6.7-112.2$ & $0.13-13.7$ & $0.03-1.23$ & $0.04-1.19$ \\
\hline & & Mean & 33.10 & 1.2 & 28.13 & 3.372 & 0.277 & 0.33 \\
\hline & & $\mathrm{SD}$ & 17.53 & 0.39 & 18.35 & 3.92 & 0.31 & 0.21 \\
\hline & & $\mathrm{COV}$ & 0.53 & 0.33 & 0.53 & 1.16 & 1.12 & 0.64 \\
\hline
\end{tabular}

This $L_{1}-L_{2}$ interpretation is a graphical method that utilizes the load-displacement curve. $L_{1}$ is defined as the endpoint of the initial linear segment. As illustrated in Fig. 5, the load and displacement are represented by $Q_{L 1}$ and $\rho_{L 1}$ respectively. $L_{2}$ is the starting point of the final line segment. The load and displacement are represented by $Q_{L 2}$ and $\rho_{L 2}$ respectively. An interpretation example based on one of the pile report data is shown in Fig. 6. Chen and Fang [14] studied the $L_{1}$ and $L_{2}$ interpretation by using many load test data and established the interrelationships among $L_{1}, L_{2}$, and several typical interpretation criteria. Their analysis showed that $L_{1}=0.5 L_{2}$, on average. This finding indicates a factor of safety of 2 if $L_{1}$ is used for the design. Moreover, $L_{1}$ should be used in SLS and $L_{2}$ should be used in ULS. Tang et al. [15] recently conducted statistical analyses to evaluate model factors in a reliability-based design for drilled shafts under axial loading with SLS and ULS.

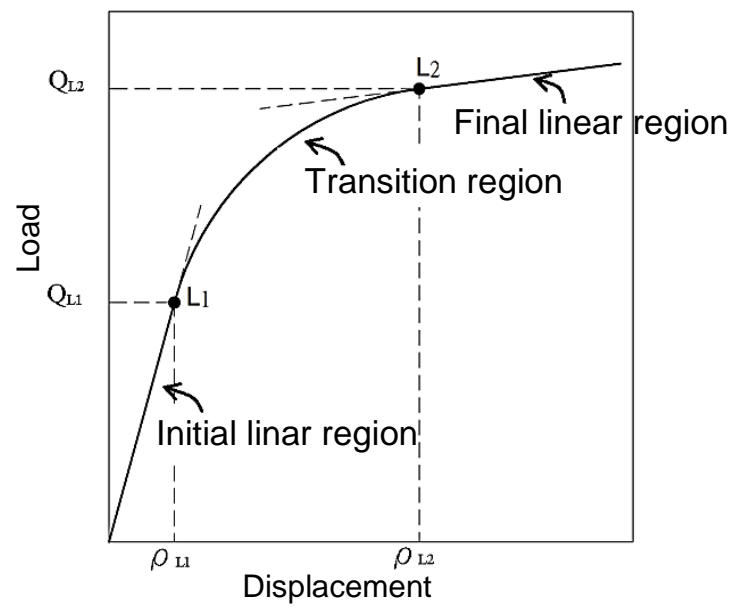

Fig. 5 Regions of load-displacement curve

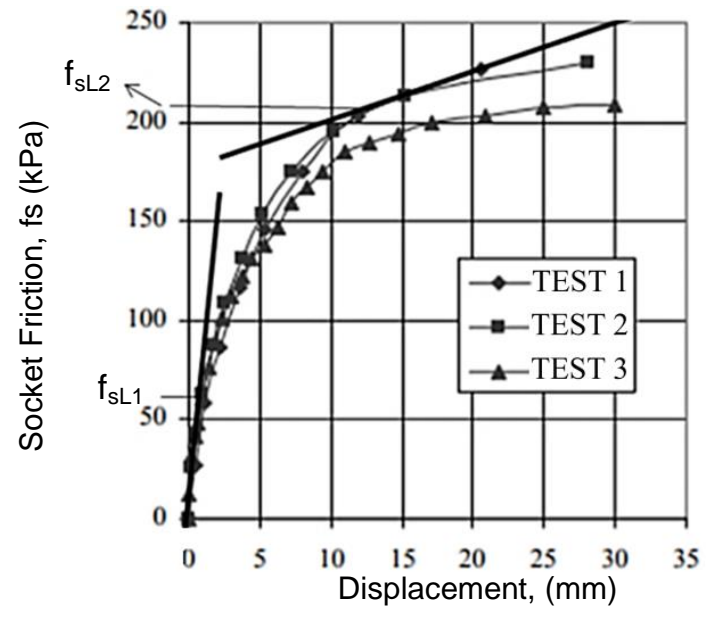

Fig. $6 \mathrm{~L}_{1}-\mathrm{L}_{2}$ interpretation of the $\mathrm{t}-\mathrm{z}$ curve example [12]

\section{Analysis Results}

\subsection{Correlation of $\alpha$ versus $q_{u}$}

Eq. (1) was used to evaluate the pile load test data for $\alpha$, and the results of the $L_{1}$ and $L_{2}$ interpretations are presented in Figs. 7 and 8, respectively, including the average results of the data obtained from 44 single pile reports. Unit side resistance was determined using the load-displacement curve or the $\mathrm{t}-\mathrm{z}$ curve.

The data in Figs. 7 and 8 were then plotted into three coordinate axes, namely (a) general coordinate, (b) semi-logarithmic, and (c) full logarithmic axes, to determine the optimum trend for each interpretation. The statistical analysis is provided in Table 3 to compare the three equations. The statistical results of the coefficient of determination $\left(\mathrm{r}^{2}\right)$, standard deviation (SD), and coefficient of variation (COV) are also listed in the figures and tables. 


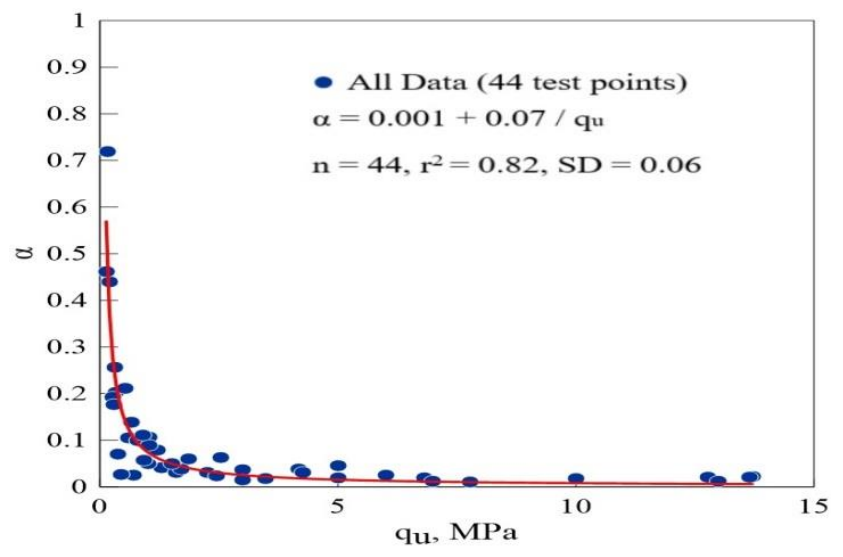

(a) general coordinate

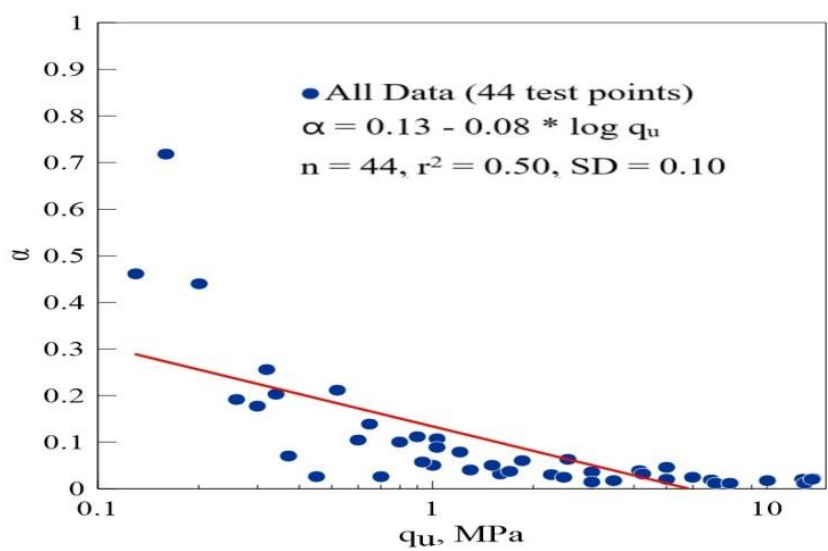

(b) semi-logarithmic coordinate

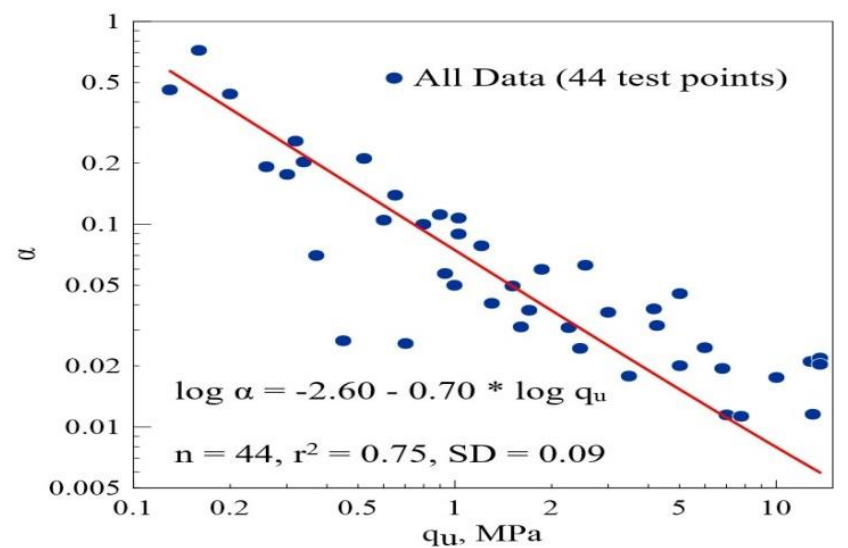

(c) full-logarithmic coordinate

Fig. $7 a-q_{u}$ relationships for $L_{1}$ interpretation

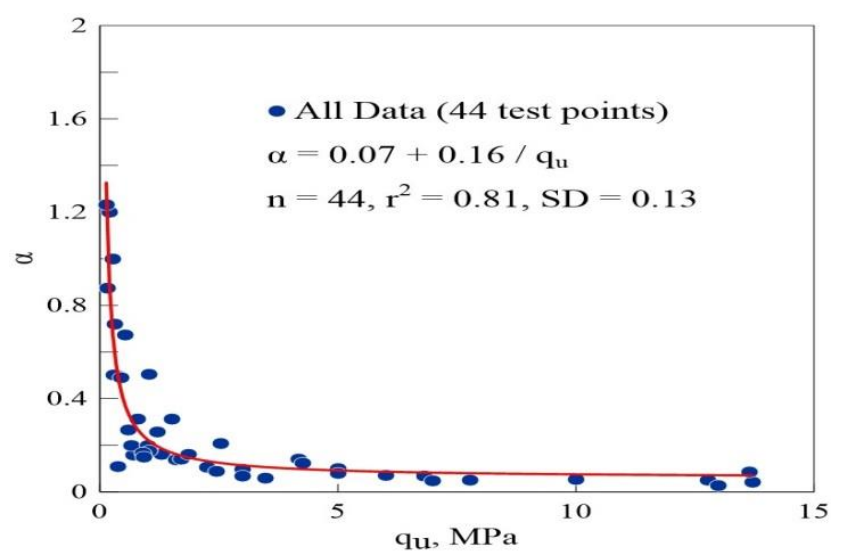

(a) general coordinate

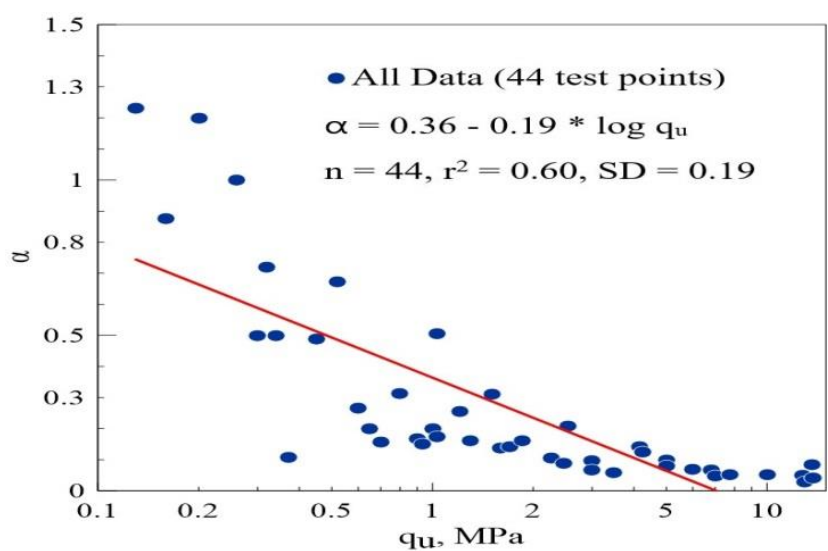

(b) semi-logarithmic coordinate

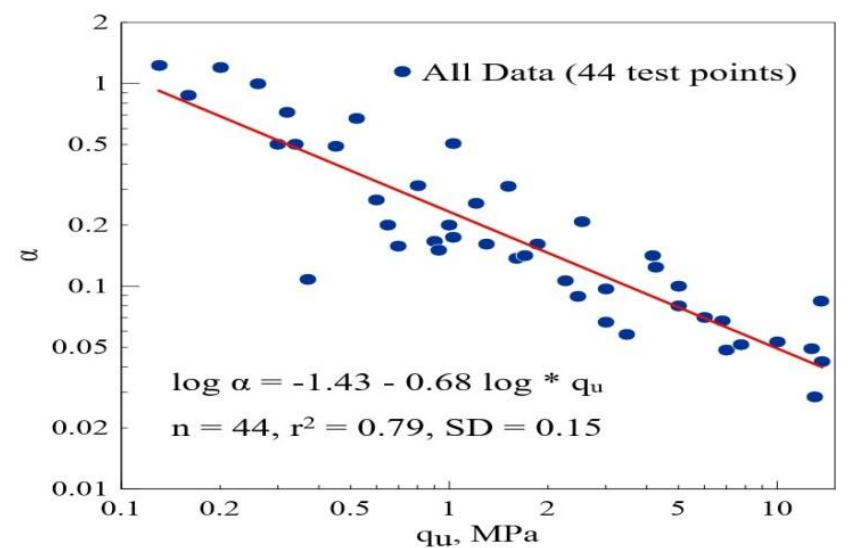

(c) full-logarithmic coordinate

Fig. $8 a-q_{u}$ relationships for $L_{2}$ interpretation 
Table 3 Statistical results for $a-q_{u}$ relationships

\begin{tabular}{|c|c|c|c|c|c|c|}
\hline $\begin{array}{c}\text { Interpretation } \\
\text { method }\end{array}$ & Coordinate form & Regression equation & $\mathrm{n}$ & $r^{2}$ & SD & $\mathrm{COV}$ \\
\hline \multirow{3}{*}{$L_{1}$} & General coordinate & $\alpha=0.01+0.07 / q_{u}$ & \multirow{3}{*}{44} & 0.82 & 0.06 & 0.59 \\
\hline & Semi-logarithmic & $\alpha=0.13-0.08 \cdot \log \left(q_{u}\right)$ & & 0.50 & 0.10 & 1.00 \\
\hline & Full logarithmic & $\log (\alpha)=-2.60-0.70 \cdot \log \left(q_{u}\right)$ & & 0.75 & 0.09 & 0.87 \\
\hline \multirow{3}{*}{$L_{2}$} & General coordinate & $\alpha=0.07+0.16 / q_{u}$ & \multirow{3}{*}{44} & 0.81 & 0.13 & 0.45 \\
\hline & Semi-logarithmic & $\alpha=0.36-0.19 \cdot \log \left(q_{u}\right)$ & & 0.60 & 0.19 & 0.66 \\
\hline & Full logarithmic & $\log (\alpha)=-1.43-0.68 \cdot \log \left(q_{u}\right)$ & & 0.79 & 0.15 & 0.51 \\
\hline
\end{tabular}

The results of the statistical analyses indicated that the three coordinate axes used in the study caused differences in terms of reliability with each interpretation used. As shown by the results, the general coordinate regression equation has the lowest COV for the $L_{1}$ and $L_{2}$ interpretations. Therefore, the general coordinate regression equation exhibits higher reliability than the other equations.

\subsection{Correlation of $\alpha$ versus $\sqrt{q_{u}}$}

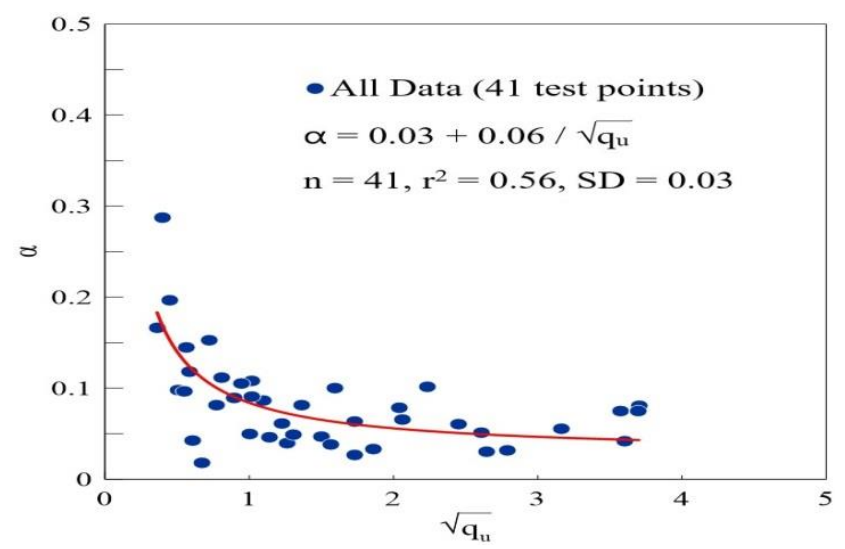

(a) general coordinate

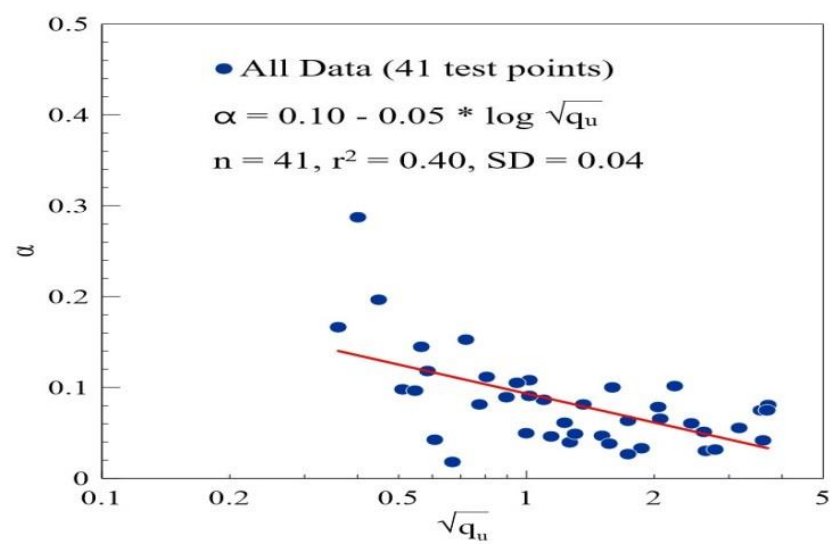

(b) semi-logarithmic coordinate

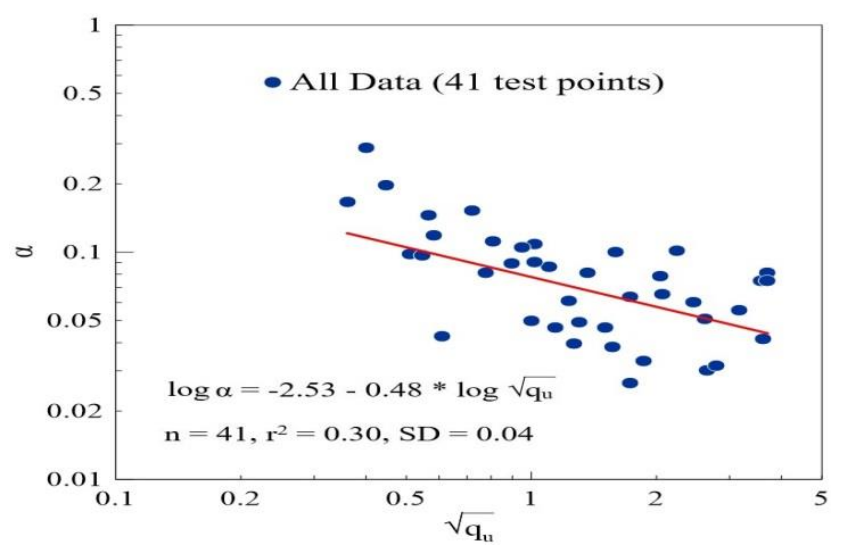

(c) full-logarithmic coordinate

Fig. $9 \alpha-\sqrt{q_{u}}$ relationships for $L_{1}$ interpretation

The analysis presented in this section is commonly used in determining the side resistance of drilled shafts socketed into rock sections. The difference is that the uniaxial compressive strength was analyzed through its root. The results showed that several discrete data points are scattered, resulted in an inconsistent plot. These data were obtained from piles socketed into mudstone $(n=3)$ because foundations embedded into mudstone tend to have a greater tip capacity than friction. Thus, these data were omitted in this section to obtain reasonable results. The new data were then plotted into (a) general coordinate, (b) semi-logarithmic, and (c) full logarithmic axes, as shown in Figs. 9 and 10 for the $L_{1}$ and $L_{2}$ interpretations respectively. The 
data were plotted in the three coordinate axes in order to determine the optimum trend for each interpretation. Statistical analysis is provided in Table 4 to compare the two interpretations used in the study.

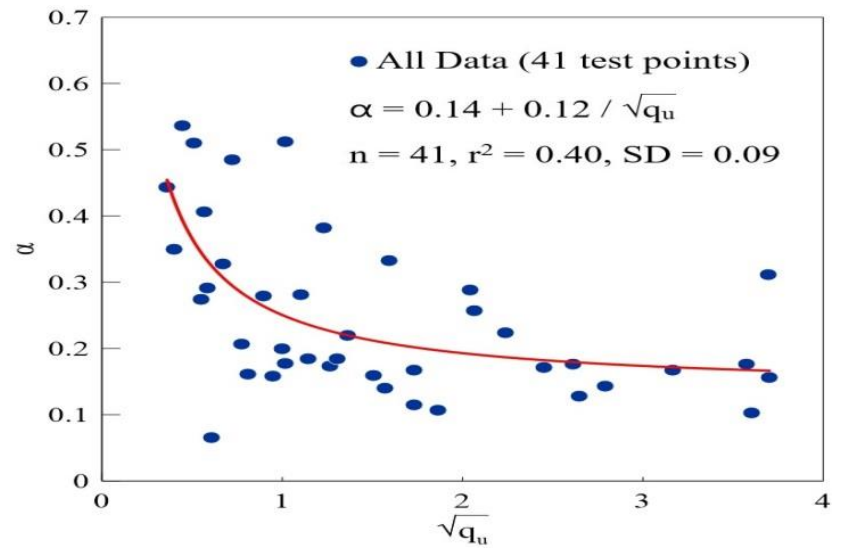

(a) general coordinate

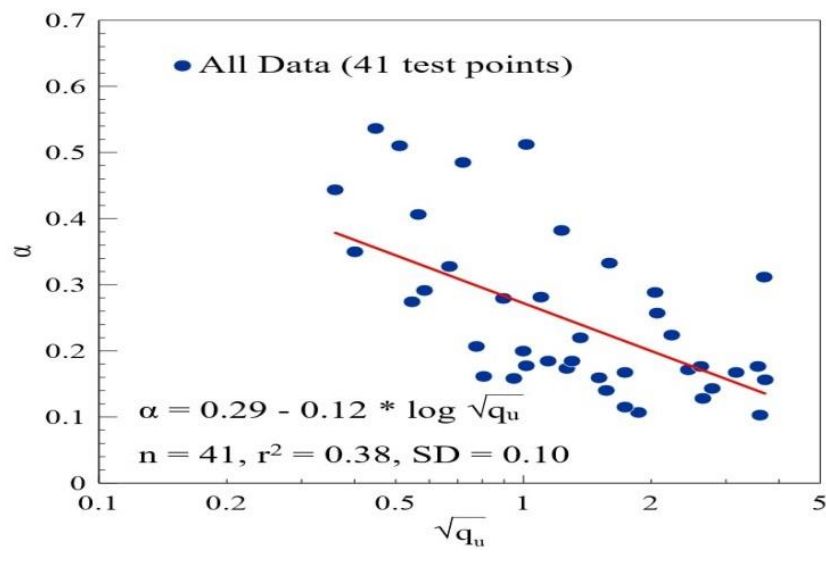

(b) semi-logarithmic coordinate

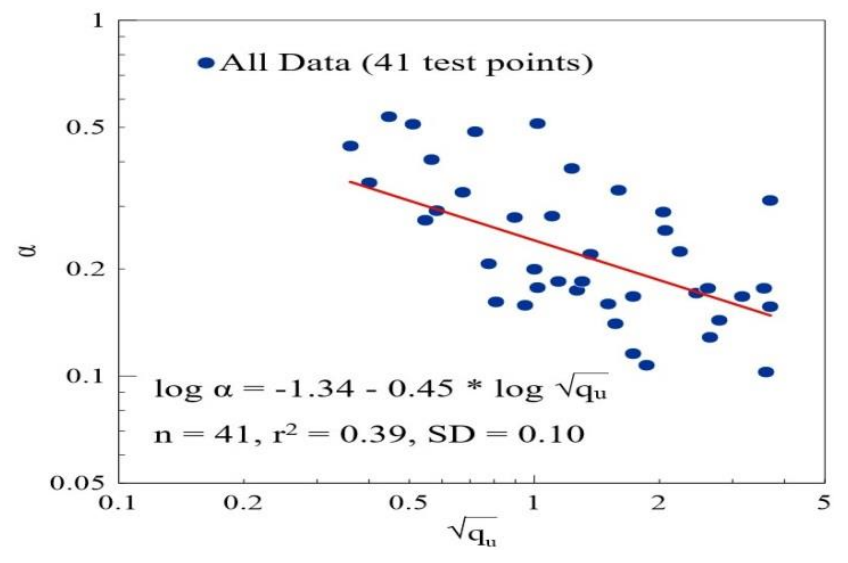

(c) full-logarithmic coordinate

Fig. $10 \alpha-\sqrt{q_{u}}$ relationships for $L_{2}$ interpretation

Table 4 Statistical results for $\alpha-\sqrt{q_{u}}$ relationships

\begin{tabular}{|c|c|c|c|c|c|c|}
\hline $\begin{array}{l}\text { Interpretation } \\
\text { method }\end{array}$ & Coordinate form & Regression equation & $\mathrm{n}$ & $r^{2}$ & SD & $\mathrm{COV}$ \\
\hline \multirow{3}{*}{$L_{1}$} & General coordinate & $\alpha=0.03+0.06 / \sqrt{q_{u}}$ & \multirow{3}{*}{41} & 0.56 & 0.03 & 0.41 \\
\hline & Semi-logarithmic & $\alpha=0.10-0.05 \cdot \log \left(\sqrt{q_{u}}\right)$ & & 0.40 & 0.04 & 0.48 \\
\hline & Full logarithmic & $\log (\alpha)=-2.53-0.48 \cdot \log \left(\sqrt{q_{u}}\right)$ & & 0.30 & 0.04 & 0.48 \\
\hline \multirow{3}{*}{$L_{2}$} & General coordinate & $\alpha=0.14+0.12 / \sqrt{q_{u}}$ & \multirow{3}{*}{41} & 0.40 & 0.09 & 0.36 \\
\hline & Semi-logarithmic & $\alpha=0.29-0.12 \cdot \log \left(\sqrt{q_{u}}\right)$ & & 0.38 & 0.10 & 0.37 \\
\hline & Full logarithmic & $\log (\alpha)=-1.34-0.45 \cdot \log \left(\sqrt{q_{u}}\right)$ & & 0.39 & 0.10 & 0.37 \\
\hline
\end{tabular}

Similarly, the general coordinate regression equation has the lowest COV for the $L_{1}$ and $L_{2}$ interpretations. Therefore, the general coordinate regression equation exhibits higher reliability than those of the semi-logarithmic and full logarithmic coordinates.

\subsection{Comparison of $\alpha$ versus $q_{u}$ and $\sqrt{q_{u}}$}

From the preceding analysis results, the regression equation developed in the general coordinate axes should be used when analyzing drilled shafts socketed into rocks. Moreover, in accordance with the COV values computed in the study, the 
$\alpha-\sqrt{q_{u}}$ relationship yielded better correlation than that of $\alpha-q_{u}$. Table 5 provides the comparison of the COV values of the $L_{1}$ and $L_{2}$ interpretations of the $\alpha-q_{u}$ and $\alpha-\sqrt{q_{u}}$ relationships. The $\alpha-\sqrt{q_{u}}$ relationship resulted in a lower COV than that of the $\alpha-q_{u}$ relationship, providing accurate results for SLS and ULS.

Fig. 4 indicates that the current proposed relation between $a$ and $\sqrt{q_{u}}$, and the range of $\alpha$ values is extremely broad and scattered. With the completion of the study, data correlation through analysis was improved, which increased the reliability of its application to SLS and ULS.

Table 5 Statistical results for $\alpha-\sqrt{q_{u}}$ relationships

\begin{tabular}{|c|c|c|c|c|c|c|}
\hline $\begin{array}{c}\text { Interpretation } \\
\text { method }\end{array}$ & Relationship & Regression equation & $\mathrm{n}$ & $\mathrm{r}^{2}$ & SD & COV \\
\hline \multirow{2}{*}{$L_{1}$} & $\alpha-q_{u}$ & $\alpha=0.01+0.07 / q_{u}$ & 44 & 0.82 & 0.06 & 0.59 \\
\cline { 2 - 8 } & $\alpha-\sqrt{q_{u}}$ & $\alpha=0.03+0.06 / \sqrt{q_{u}}$ & 41 & 0.56 & 0.03 & 0.41 \\
\hline \multirow{2}{*}{$L_{2}$} & $\alpha-q_{u}$ & $\alpha=0.07+0.16 / q_{u}$ & 44 & 0.81 & 0.13 & 0.45 \\
\cline { 2 - 8 } & $\alpha-\sqrt{q_{u}}$ & $\alpha=0.14+0.12 / \sqrt{\mathrm{q}_{\mathrm{u}}}$ & 41 & 0.40 & 0.09 & 0.36 \\
\hline
\end{tabular}

\section{Conclusions}

This study utilized numerous load test data to evaluate the side resistance of drilled shafts socketed into rocks. Upon analysis of the test results, the following conclusions were drawn.

1. This study developed $\alpha-q_{u}$ and $\alpha-\sqrt{q_{u}}$ relationships plotted into three coordinate axes. The three coordinate axes were then compared, and the analysis results showed that the general coordinate axes regression equation exhibited better reliability than the semi-logarithmic and full logarithmic axes equations.

2. The study proved that using the $\alpha-\sqrt{q_{u}}$ relationship is reliable in the analysis of drilled shafts socketed into rocks for the $L_{1}$ and $L_{2}$ interpretations because of its lower COV value than that of the $\alpha-q_{u}$ relationship. The relations recommended in this study also yielded higher reliability than previous ones.

3. To determine SLS, the $L_{1}$ interpretation of the $\alpha-\sqrt{q_{u}}$ relationship developed in the study using the regression equation, $\alpha=0.03+0.06 / \sqrt{q_{u}}$, is recommended for the developed equation, $\mathrm{r}^{2}=0.56, \mathrm{SD}=0.03$, and $\mathrm{COV}=0.41$.

4. To determine ULS, the $L_{2}$ interpretation of the $\alpha-\sqrt{q_{u}}$ relationship developed in the study using the regression equation, $\alpha=0.14+0.12 / \sqrt{\mathrm{q}_{\mathrm{u}}}$, is recommended for the developed equation, $\mathrm{r}^{2}=0.40, \mathrm{SD}=0.09$, and $\mathrm{COV}=0.36$.

\section{Acknowledgments}

This research work was supported by the Ministry of Science and Technology (MOST), Taiwan, under grant 107-2221-E-033-014.

\section{Conflicts of Interest}

The authors declare no conflict of interest.

\section{References}

[1] C. V. Stas and F. H. Kulhawy, "Some observations on undrained side resistance of drilled shafts," Foundation Engineering, Current Principles and Practices, ASCE, pp. 1011-1025, 1984. 
[2] Y. J. Chen and F. H. Kulhawy, "Case history evaluation of drilled shafts behavior," Electric Power Research Institute, Palo Alto, Report TR-104601, p. 356, 1994.

[3] Y. J. Chen and F. H. Kulhawy, "Evaluation of undrained side and tip resistances for drilled shafts," Proc. Soil and Rock America, vol. 2, pp. 1963-1968, 2003.

[4] M. C. Marcos and Y. J. Chen, "Evaluation of side resistance of driven precast concrete piles," Materials Science and Engineering, IOP, vol. 658, no. 1, 012005, 2019.

[5] M. C. Marcos, and Y. J. Chen, "Applicability of various load test interpretation criteria in measuring driven precast concrete pile uplift capacity,” International Journal of Engineering and Technology Innovation, vol. 8, no. 2, pp. 118-132, 2018.

[6] F. H. Kulhawy and R. E. Goodman, Foundation in rock, ground engineers reference book, Butterworth and Co. Ltd., 2005.

[7] P. Hooley and S. R. L. Brooks, "The ultimate shaft frictional resistance mobilized by bored piles in overconsolidated clays and socked into weak and weathered rock," The Engineering Geology of Weak Rock, Balkema, pp. 447-455, 1993.

[8] American Association of State Highway and Transportation Official (AASHTO), Standard Specifications for Highway Bridges, 1992.

[9] R. G. Horvath, T. C. Kenney, and P. Kozicki, "Methods of improving the performance of drilled piers in weak rock," Canadian Geotechnical Journal, vol. 20, no. 4, pp. 758-772, 1983.

[10] C. S. Ku, J. Weng, X. Liu, and X. Lin, "Study on side resistance of soft rock foundations,” Proc. Rock Engineering Symposium, Tamsui, pp. 224-231, 2007.

[11] Z. Y. Yang, J. Q. Shiau, J. Ching, Y. S. Lee, and C. J. Chen, "Side resistance of pile socketed into rock in Taiwan area," Proc. Rock Engineering Symposium, Kaohsiung, pp. 75-83, 2010.

[12] C. C. Hsiao, "Evaluation of side resistance for drilled shafts socketed into rocks," Master Thesis, Department of Civil Engineering, Chung Yuan Christian University, 2018.

[13] A. Hirany and F. H. Kulhawy, "Interpretation of load tests on drilled shafts: axial compression," Foundation Engineering: Current Principles \& Practices (GSP22), ASCE, New York, pp.1150-1159, 1989.

[14] Y. J. Chen and Y. C. Fang, "Critical evaluation of compression interpretation criteria for drilled shafts," Journal of Geotechnical and Geoenvironmental Engineering, ASCE, vol. 135, no. 8, pp. 1056-1069, 2009.

[15] C. Tang, K. K. Phoon, and Y. J. Chen, "Statistical analyses of model factors in reliability-based limit state design of drilled shafts under axial loading," Journal of Geotechnical and Geoenvironmental Engineering, ASCE, vol. 145, no. 9, pp. 04019042-1-19, 2019.

Copyright $(\mathrm{C}$ by the authors. Licensee TAETI, Taiwan. This article is an open access article distributed under the terms and conditions of the Creative Commons Attribution (CC BY-NC) license (https://creativecommons.org/licenses/by-nc/4.0/). 